\title{
Patients with heart failure with preserved ejection fraction and low levels of natriuretic peptides
}

\author{
W.C. Meijers ${ }^{1} \cdot$ T. Hoekstra ${ }^{1} \cdot$ T. Jaarsma ${ }^{2}$ D.J. van Veldhuisen ${ }^{1} \cdot$ R.A. de Boer ${ }^{1}$
}

Published online: 3 March 2016

(C) The Author(s) 2016. This article is published with open access at Springerlink.com

\begin{abstract}
Aims Heart failure with preserved ejection fraction (HF$\mathrm{pEF}$ ) is common and its management remains difficult. Btype natriuretic peptide (BNP) levels are used to diagnose heart failure, and as an entry criterion for inclusion into trials. We investigated a population of HFpEF patients who had been randomised into a study based on clinical parameters, and compared those with low BNP levels to those with elevated BNP levels.

Methods We examined patients who had been enrolled in the Coordinating study evaluating Outcomes of Advising and Counselling in Heart Failure $(\mathrm{COACH})$, with preserved left ventricular ejection fraction ( $\mathrm{LVEF} \geq 40 \%)$, and compared those with low BNP $(<100 \mathrm{pg} / \mathrm{ml} ; n=30)$ to those with elevated BNP ( $\geq 100 \mathrm{pg} / \mathrm{ml} ; n=127)$. Baseline characteristics, comorbidities, biomarkers, quality of life, and outcome parameters (hospitalisations and death) were compared between the groups. To validate our findings, we repeated all analyses for NT-proBNP $(<300 \mathrm{pg} / \mathrm{ml}$ and $\geq 300 \mathrm{pg} / \mathrm{ml})$.

Results Patients were similar with regard to most clinical characteristics (including age, sex, and LVEF), biomarkers, and comorbidities. In contrast, patients with a low BNP
\end{abstract}

Electronic supplementary material The online version of this article (doi:10.1007/s12471-016-0816-8) contains supplementary material, which is available to authorized users.

R.A. de Boer

r.a.de.boer@umcg.nl

1 Department of Cardiology, University Medical Center, University of Groningen, Groningen, The Netherlands

2 Faculty of health sciences, Linköping University, Linköping, Sweden had higher body mass index levels $\left(31 \mathrm{~kg} / \mathrm{m}^{2}\right.$ vs. $27 \mathrm{~kg} / \mathrm{m}^{2}$; $p<0.01)$ and lower cardiac troponin I $(9 \mathrm{pg} / \mathrm{ml}$ vs. $15 \mathrm{pg} /$ $\mathrm{ml} ; p=0.02$ ). In addition, these patients were less frequently prescribed diuretics and beta-blockers. No differences in quality of life, heart failure related symptoms and the primary and secondary outcomes were observed between these groups. These observations were confirmed for NT-proBNP. Conclusion Among the patients with clinically diagnosed HFpEF, those with low BNP are strikingly similar to those with elevated BNP levels, except for BMI, which was significantly higher in these patients.

Keywords Heart failure - Preserved ejection fraction . Quality of life - B-type Natriuretic peptide - Biomarkers · Symptoms

\section{Introduction}

Heart failure with preserved ejection fraction (HFpEF) is a prevalent cause of cardiovascular morbidity and mortality [1] and the incidence is still increasing [2]. Patients with either HFpEF or heart failure with reduced ejection fraction (HFrEF) are generally comparable regarding signs, symptoms and quality of life (QoL) [3]. But HFpEF patients are more often elderly, female and more frequently have hypertension, atrial fibrillation and other comorbidities [4], whereas HFrEF patients have a higher prevalence of coronary artery disease and myocardial infarction [5]. Due to the presence of these comorbidities, often with heart failure-like symptoms, the diagnosis of HFpEF is difficult, and in fact some patients with assumed HFpEF might not have heart failure, but suffer from other conditions such as anaemia, lung disease, or depression. 
The guidelines of the European Society of Cardiology (ESC) state that for a diagnosis of heart failure, untreated patients with symptoms of heart failure should have at least B-type natriuretic peptide (BNP) levels of $100 \mathrm{pg} /$ $\mathrm{ml}$ to confirm a possible diagnosis of heart failure (or NTproBNP levels of $300 \mathrm{pg} / \mathrm{ml}$ ) [6]. In a very recent metaanalysis [7], 37 unique study cohorts with over 15,000 test results were available, and the proposed rule-out threshold for BNP recommended by the 2012 ESC guidelines was shown to have excellent ability to exclude acute heart failure. However, no distinction could be made between HFpEF and HFrEF patients as data on BNP cut-off points in $\mathrm{HFpEF}$ are rare and ill-validated. Interestingly, a group of HFpEF patients with BNP levels below 100 do not officially meet the diagnostic criteria. This raises the question whether and how these patients, who are a clinical reality, differ from patients with HFpEF and BNP levels $\geq 100 \mathrm{pg} /$ $\mathrm{ml}$.

Therefore, we compared HFpEF patients with or without low BNP levels for their baseline characteristics, heart failure symptoms, biomarkers, QoL measurements and outcome parameters.

\section{Methods}

\section{Patient population}

Data were collected as part of the Coordinating study evaluating Outcomes of Advising and Counselling in Heart failure $(\mathrm{COACH})$, as described in detail elsewhere $[8,9]$. In brief, patients who were admitted for heart failure were enrolled in $\mathrm{COACH}$ before discharge, and randomised to standard of care or to nurse-led interventions. In the current sub-study only patients with a left ventricular ejection fraction (LVEF) $\geq 40 \%$, with complete data on BNP and QoL were included, as previously described [10]. The study was performed in accordance with the principles outlined in the Declaration of Helsinki and was approved by the Medical Ethics Committee in each participating centre. All subjects provided informed consent. Further details are described in the Online Supplement.

\section{Endpoints}

The primary outcome was all-cause mortality and/or rehospitalisation for heart failure after 18 months. Secondary outcomes were all-cause mortality, heart failure rehospitalisation, cardiovascular rehospitalisation, or all-cause rehospitalisation after 18 months. We also analysed all-cause mortality after 36 months. An independent endpoint committee adjudicated all endpoints [11].

\section{Biochemical measurements}

An extensive description of the assays used can be found in the Online supplement.

\section{Quality of life and heart failure symptoms}

QoL measurements were collected during hospitalisation and were assessed in two different ways. Global wellbeing was assessed by Cantril's Ladder of Life [12] and the Medical Outcome Study 36-item General Health Survey (RAND36) assessed disease generic QoL [13]. Both established measurements are further explained in the Online Supplement together with the assessment of heart failure symptoms.

\section{Statistical analyses}

Descriptive statistics were used to characterise the study population. Cox proportional hazards regression analyses were performed to adjust for the time to event. KaplanMeier curves were constructed for the different time to event evaluations. We repeated our analyses for patients with low NT-proBNP and high NT-proBNP levels.

$P$-values below $<0.05$ were considered to denote significant differences. Analyses were performed with STATA software (version 13.0, Stata Corp, College Station, Texas, USA).

\section{Results}

\section{Patient characteristics}

Of the 1023 patients enrolled, 157 patients had an LVEF $\geq 40 \%$, and complete data on BNP and QoL. Patients had a mean age of $73( \pm 9), 45 \%$ were female, and they had a mean LVEF of $51 \%( \pm 9 \%)$ and a median BNP level of $352 \mathrm{pg} / \mathrm{ml}$ [149-791 $\mathrm{pg} / \mathrm{ml}]$. This is substantially lower than in the overall COACH cohort (median BNP $447 \mathrm{pg} /$ $\mathrm{ml}[195-888 \mathrm{pg} / \mathrm{ml}])$. Of the 157 patients with an LVEF $\geq 40 \%$, 30 patients $(19 \%)$ had BNP levels lower than $100 \mathrm{pg} / \mathrm{ml}$. Patients with low BNP levels had a higher body mass index (BMI; $31 \mathrm{~kg} / \mathrm{m}^{2}$ vs. $\left.27 \mathrm{~kg} / \mathrm{m}^{2} ; p<0.01\right)$ and were less often treated with beta-blockers and diuretics (30\% vs. $65 \% ; p<0.001$ and $87 \%$ vs. $98 \%$, respectively, $p<0.01$ ) (Table 1). However, other important clinical characteristics were very comparable between the HFpEF patients with low or elevated BNP. Likewise, comorbidities including chronic obstructive pulmonary disease, diabetes and anaemia were equally frequent in patients with either low or high BNP levels. Biomarkers commonly measured in heart failure patients such as cystatin C, galectin-3, interleukin 6 , and 
Table 1 Baseline characteristics of patients with HFpEF enrolled in the COACH study: overall and stratified by BNP levels

\begin{tabular}{|c|c|c|c|c|}
\hline Characteristics & Total $(n=157)$ & $\mathrm{BNP}<100 \mathrm{pg} / \mathrm{ml}(n=30)$ & $\mathrm{BNP} \geq 100 \mathrm{pg} / \mathrm{ml}(n=127)$ & $p$-value \\
\hline$\overline{\operatorname{Age}(\mathrm{y}), \text { mean }(\mathrm{SD})}$ & $73(9)$ & $72(9)$ & $73(9)$ & 0.51 \\
\hline Female, $n(\%)$ & $71(45)$ & $12(40)$ & $59(47)$ & 0.52 \\
\hline SBP (mmHg), mean (SD) & $125(22)$ & $125(25)$ & $125(22)$ & 0.94 \\
\hline DBP (mmHg), mean (SD) & $69(13)$ & $73(16)$ & $68(12)$ & 0.04 \\
\hline Heart rate (bpm), mean (SD) & $72(12)$ & $73(13)$ & $72(12)$ & 0.51 \\
\hline BMI $\left(\mathrm{kg} / \mathrm{m}^{2}\right)$, mean $(\mathrm{SD})$ & $28(6)$ & $31(7)$ & $27(5)$ & $<\mathbf{0 . 0 1}$ \\
\hline \multicolumn{5}{|l|}{ HF history } \\
\hline NYHA class II & $88(56)$ & $12(40)$ & $76(60)$ & 0.10 \\
\hline III & $61(39)$ & $15(50)$ & $46(36)$ & \\
\hline IV & $8(5)$ & $3(10)$ & $5(4)$ & \\
\hline LVEF (\%), mean (SD) & $51(9)$ & $53(10)$ & $50(8)$ & 0.06 \\
\hline Previous MI, $n(\%)$ & $51(33)$ & $6(20)$ & $45(35)$ & 0.10 \\
\hline Distance 6MWT, mean (SD) & $212(131)$ & $169(106)$ & $222(135)$ & 0.09 \\
\hline \multicolumn{5}{|l|}{ Comorbidities } \\
\hline Asthma & $6(4)$ & $0(0)$ & $6(5)$ & 0.22 \\
\hline Atrial fibrillation & $79(50)$ & $15(50)$ & $64(50)$ & 0.97 \\
\hline Anaemia & $43(43)$ & $6(33)$ & $37(45)$ & 0.38 \\
\hline COPD & $53(34)$ & $11(37)$ & $42(33)$ & 0.71 \\
\hline Diabetes & $45(29)$ & $8(27)$ & $37(29)$ & 0.79 \\
\hline Hypertension & $78(50)$ & $16(53)$ & $62(49)$ & 0.66 \\
\hline Stroke & $26(17)$ & $5(17)$ & $21(17)$ & 0.99 \\
\hline \multicolumn{5}{|l|}{ Treatment } \\
\hline $\mathrm{ACEi} / \mathrm{ARB}, n(\%)$ & $123(78)$ & $25(83)$ & $98(77)$ & 0.46 \\
\hline$\beta$-Blocker, $n(\%)$ & $92(59)$ & $9(30)$ & $83(65)$ & $<0.001$ \\
\hline Loop diuretic, $n(\%)$ & $151(96)$ & $26(87)$ & $125(98)$ & $<0.01$ \\
\hline MRA, $n(\%)$ & $67(43)$ & $11(37)$ & $56(44)$ & 0.46 \\
\hline Digoxin, $n(\%)$ & $49(31)$ & $8(27)$ & $41(32)$ & 0.55 \\
\hline \multicolumn{5}{|l|}{ Laboratory measurements } \\
\hline Sodium (mmol/1), mean (SD) & $139(4)$ & $138(6)$ & $139(4)$ & 0.31 \\
\hline Potassium (mmol/1), mean (SD) & $4(1)$ & $4(1)$ & $4(1)$ & 0.44 \\
\hline Urea (mmol/l), mean (SD) & $14(8)$ & $16(9)$ & $13(8)$ & 0.11 \\
\hline Creatinine $(\mu \mathrm{mol} / \mathrm{l})$, mean $(\mathrm{SD})$ & $127(61)$ & $129(51)$ & $126(63)$ & 0.84 \\
\hline eGFR $\left(\mathrm{ml} / \mathrm{min}\right.$ per $\left.1.73 \mathrm{~m}^{2}\right)$, mean (SD) & $54(21)$ & $51(16)$ & $54(22)$ & 0.42 \\
\hline \multicolumn{5}{|l|}{ Biomarkers } \\
\hline $\mathrm{BNP}(\mathrm{pg} / \mathrm{ml})$, median [IQR] & $352[149-791]$ & $53[34-72]$ & $457[244-864]$ & $<\mathbf{0 . 0 0 1}$ \\
\hline Cystatin C $(\mu \mathrm{g} / \mathrm{ml})$, median [IQR] & $11.3[7.8-15.7]$ & $11.2[9.2-19.0]$ & $11.4[7.7-15.7]$ & 0.84 \\
\hline Galectin-3 (ng/ml), median [IQR] & $19[15-25]$ & 19 [14-27] & $19[15-25]$ & 0.77 \\
\hline Interleukin $6(\mathrm{ng} / \mathrm{ml})$, median [IQR] & $12[7-23]$ & $11[6-22]$ & $12[7-24]$ & 0.70 \\
\hline NGAL (ng/ml), median [IQR] & $113[87-165]$ & $147[81-181]$ & 109 [87-147] & 0.34 \\
\hline Troponin I (pg/ml), median [IQR] & $14[6-31]$ & $9[4-13]$ & $15[7-35]$ & 0.02 \\
\hline
\end{tabular}

$B N P$ B-type natriuretic peptide, $S B P$ systolic blood pressure, $D B P$ diastolic blood pressure, $B M I$ body mass index, $H F$ heart failure, $N Y H A$ New York Heart Association, $L V E F$ left ventricular ejection fraction, $M I$ myocardial infarction, $6 M W T$ 6-minute walk test, $C O P D$ chronic obstructive pulmonary disease, $A C E i$ angiotensin-converting-enzyme inhibitor, $A R B$ angiotensin II receptor blocker, $M R A$ mineralocorticoid receptor antagonist, $e G F R$ estimated glomerular filtration rate, $N G A L$ neutrophil gelatinase-associated lipocalin.

neutrophil gelatinase-associated lipocalin (NGAL) showed no differences between the two groups, but cardiac troponin I (cTnI) was significantly lower in patients with low BNP levels $(9 \mathrm{pg} / \mathrm{ml}$ vs. $15 \mathrm{pg} / \mathrm{ml} ; p=0.02)$. BNP levels gradually decreased stratified by the World Health Organisation BMI classification scale (underweight $<18.5 \mathrm{~kg} / \mathrm{m}^{2}$; normal range $18.5-25 \mathrm{~kg} / \mathrm{m}^{2}$; overweight $25-30 \mathrm{~kg} / \mathrm{m}^{2}$; obese $\left.>30 \mathrm{~kg} / \mathrm{m}^{2}\right)($ p-trend $<0.001)$ (Fig. 1).

\section{Quality of life}

The mean score on global well-being, as measured with Cantril's Ladder of Life, did not differ significantly between HFpEF patients with low BNP levels and high BNP levels (Table 2). Also, no significant differences were observed between the two groups in any of the dimensions of the RAND36 (Table 2). 


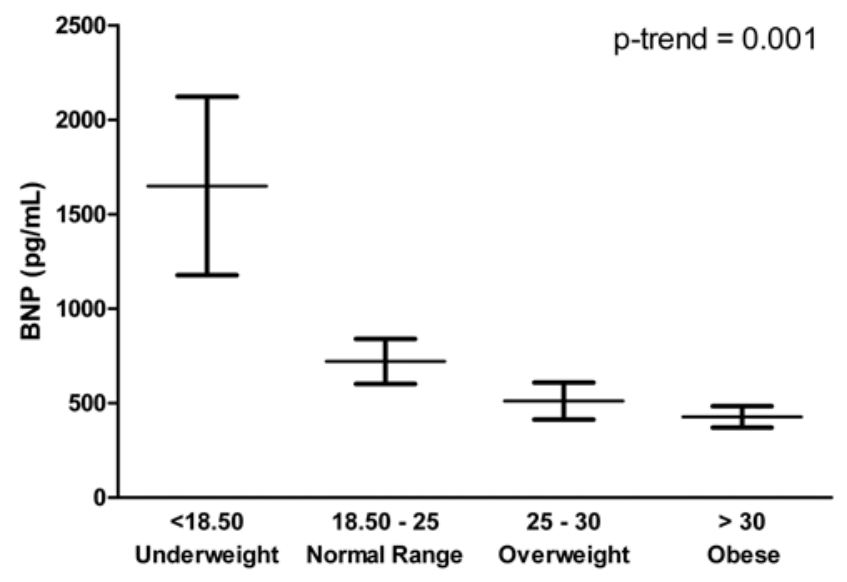

Fig. 1 BNP levels stratified by the World Health Organization BMI classification scale in HFpEF patients

\section{Symptoms of heart failure}

HFpEF patients in the COACH study were very symptomatic: patients reported on average four symptoms of heart failure. The most reported symptoms of heart failure were dyspnoea (96\%) and fatigue (88\%). Patients with low BNP levels did not differ in reported symptoms from patients with high BNP levels (Table 2).

\section{Low BNP and predictive value}

In the unadjusted Cox proportional hazard analyses no significant prediction was observed for patients with low BNP levels regarding various outcome parameters (Table 3).
Table 3 Cox proportional hazard analyses for different endpoints, comparing subjects with low BNP vs. high BNP

\begin{tabular}{llll}
\hline Endpoint & Hazard ratio & $95 \%$ CI & $P$-value \\
\hline $\mathbf{1 8}$ months & & & \\
$\begin{array}{l}\text { All-cause mortality \& } \\
\text { HF rehospitalisation }\end{array}$ & 0.63 & $0.33-1.23$ & 0.179 \\
All-cause mortality & 0.94 & $0.44-2.02$ & 0.877 \\
HF rehospitalisation & 0.45 & $0.18-1.14$ & 0.091 \\
CV rehospitalisation & 0.96 & $0.54-1.71$ & 0.883 \\
All-cause rehospitalisation & 0.53 & $0.24-1.17$ & 0.117 \\
$\mathbf{3 6}$ months & & & \\
All-cause mortality & 0.84 & $0.50-1.39$ & 0.493 \\
\hline$H F$ heart failure $C V$ cardiovascular & &
\end{tabular}

$H F$ heart failure, $C V$ cardiovascular.

Kaplan-Meier curves and the log-rank test on all the outcomes showed no significant differences when patients were stratified according to BNP levels (Fig. 2).

\section{NT-proBNP}

All analyses were also performed using NT-proBNP levels below and above $300 \mathrm{pg} / \mathrm{ml}$; similar observations were made as with BNP. Results are presented in Supplementary Tables 1, 2 and 3 and Supplementary Fig. 1.

\section{Discussion}

The main finding of our study is that a group of patients exists who present and are admitted with heart failure symptoms and who, according to the current ESC guidelines, are not likely to be diagnosed with $\mathrm{HFpEF}$ because of a too

Table 2 Quality of life and symptoms of patients with HFpEF enrolled in the COACH study: overall and stratified by BNP levels

\begin{tabular}{|c|c|c|c|c|}
\hline Characteristics & Total $(n=157)$ & $\mathrm{BNP}<100 \mathrm{pg} / \mathrm{ml}(n=30)$ & $\mathrm{BNP} \geq 100 \mathrm{pg} / \mathrm{ml}(n=127)$ & $p$-value \\
\hline \multicolumn{5}{|l|}{ Ladder of Life } \\
\hline Well-being & $6(2)$ & $6(2)$ & $6(2)$ & 0.60 \\
\hline \multicolumn{5}{|l|}{ RAND-36 } \\
\hline Physical functioning, mean (SD) & $33(25)$ & $27(21)$ & $34(26)$ & 0.15 \\
\hline Social functioning, mean (SD) & $58(31)$ & $61(32)$ & $57(31)$ & 0.51 \\
\hline Role limitation physical, mean (SD) & $18(33)$ & $18(32)$ & $18(33)$ & 0.93 \\
\hline Role limitation emotional, mean (SD) & $52(46)$ & $51(47)$ & $53(46)$ & 0.86 \\
\hline Mental health, mean (SD) & $67(21)$ & $63(21)$ & $67(21)$ & 0.32 \\
\hline Bodily pain, mean (SD) & $62(34)$ & $59(35)$ & $63(33)$ & 0.49 \\
\hline General health, mean (SD) & $43(18)$ & $38(19)$ & $44(18)$ & 0.10 \\
\hline Health change, mean (SD) & $27(23)$ & $26(20)$ & $27(24)$ & 0.84 \\
\hline \multicolumn{5}{|l|}{ Symptoms } \\
\hline Oedema, $n(\%)$ & $108(69 \%)$ & $25(83 \%)$ & $83(65 \%)$ & 0.06 \\
\hline Sleep disturbance, $n(\%)$ & $105(67 \%)$ & $18(60 \%)$ & $87(69 \%)$ & 0.37 \\
\hline Fatigue, $n(\%)$ & $138(88 \%)$ & $26(87 \%)$ & $112(88 \%)$ & 0.82 \\
\hline Dyspnoea, $n(\%)$ & $150(96 \%)$ & $30(100 \%)$ & $120(95 \%)$ & 0.19 \\
\hline Cough, $n(\%)$ & $101(64 \%)$ & $17(57 \%)$ & $84(66 \%)$ & 0.33 \\
\hline Loss of appetite, $n(\%)$ & $76(48 \%)$ & $10(33 \%)$ & $66(52 \%)$ & 0.07 \\
\hline Total number of symptoms $(0-6)$ & $4.3(1.3)$ & $4.2(1.3)$ & $4.3(1.2)$ & 0.57 \\
\hline
\end{tabular}

$B N P$ B-type natriuretic peptide. 
KEY MESSAGE HFpEF patients with low BNP levels do not have a favorable outcome.
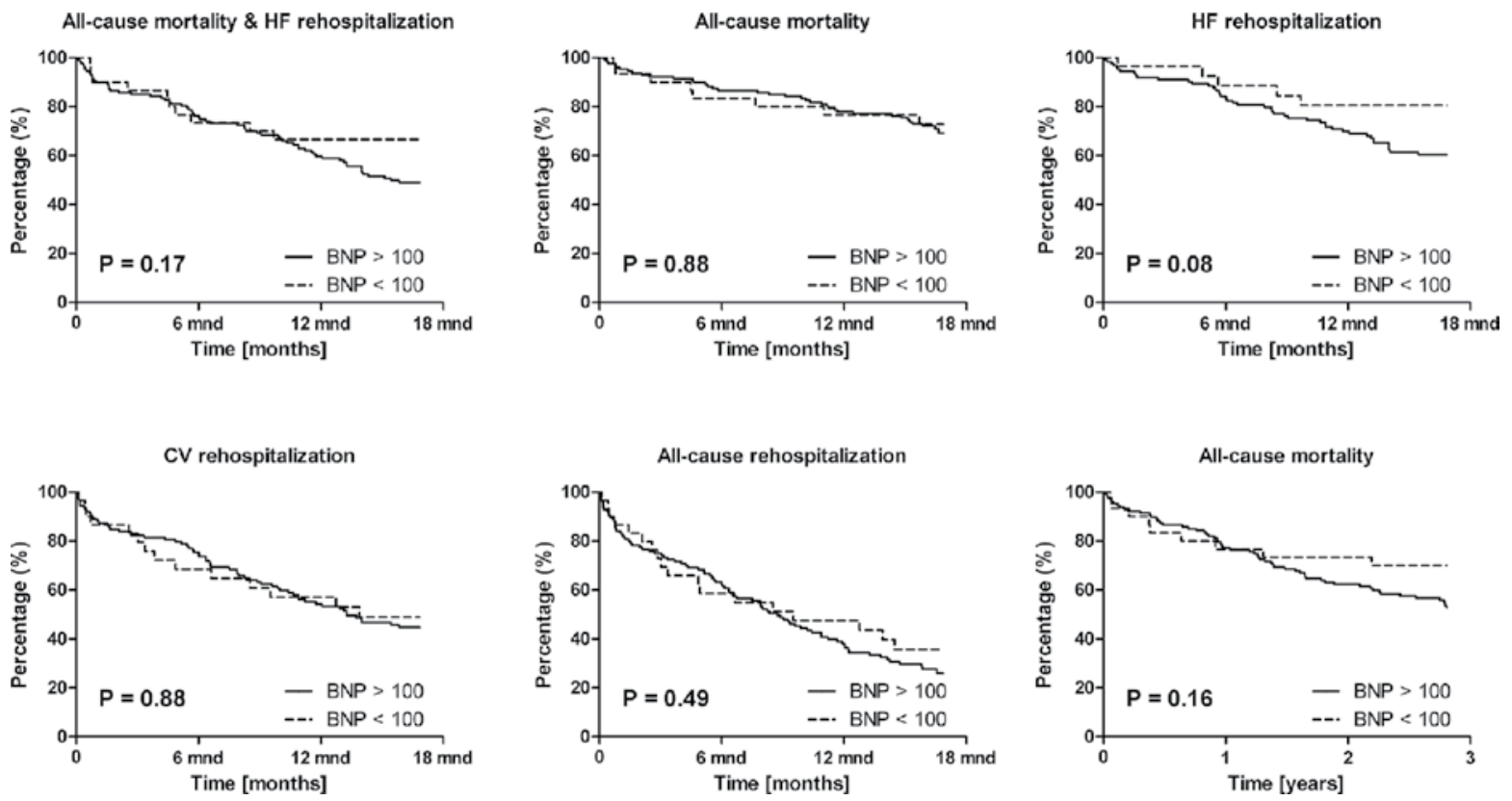

Fig. 2 Kaplan-Meier curves for various outcome parameters in patients with HFpEF, stratified by BNP level

low BNP level. These patients suffer at least as much from their condition as patients who do meet the diagnostic criteria of HFpEF. Further, they do not substantially differ from patients with HFpEF and BNP levels $\geq 100 \mathrm{pg} / \mathrm{ml}$ on a broad range of characteristics and heart failure symptoms. Most strikingly, the major difference was the higher BMI levels. Regarding different outcome parameters, we observed no differences between patients with low or high BNP levels, although we had limited power to ascertain this.

\section{HFpEF and BNP levels}

Although there is growing interest in $\mathrm{HFpEF}$, there is limited understanding about the pathology of HFpEF. Natriuretic peptide levels have been advocated to aid the diagnosis of HFpEF. But our findings are in concert with emerging literature that natriuretic peptide testing in HFpEF is not straightforward. Yamamoto et al. have already stated that we should be cautious in using BNP alone in the diagnostic work-up, because BNP concentrations increase in normal, healthy older and/or female individuals, and in those with renal dysfunction and atrial fibrillation, and decrease in obese subjects [14].

So although BNP levels have powerful prognostic value, the diagnostic value of this biomarker is less clear. The ESC Heart Failure guidelines of 2008 introduced a requirement of plasma BNP levels $\geq 100 \mathrm{pg} / \mathrm{ml}$ for diagnosing heart failure, in addition to the presence of symptoms of heart failure. As a result, patients with heart failure symptoms but with BNP levels $<100 \mathrm{pg} / \mathrm{ml}$ do not 'officially' have a diagnosis of heart failure, and physicians are advised to actively seek an alternative diagnosis. Therefore, it is expected that the prevalence of comorbidities among this patient population will be higher than in patients with high BNP levels. A recent paper by Paulus et al. hypothesises that comorbidities may actually drive the myocardial dysfunction in HFpEF [15]. However, in our study we cannot clearly establish such a gradient between BNP levels and the number of comorbidities. The one exception was BMI. It has been published by others $[16,17]$ that BMI is a strong confounder of natriuretic peptides. Therefore, patients with a high BMI and low BNP levels may have 'concealed' heart failure, with disproportionately low BNP levels not properly reflecting left ventricular wall stress.

Usually, BNP directly reflects left ventricular wall stress, but apparently BMI interferes with this relationship. The one finding that validates the notion that lower BNP really associates with lower stress to the heart is our observation that also cTnI was lower in patients with lower BNP. Cardiac troponins are increasingly recognised as a major prognostic factor in heart failure [18]. Whether obesity has a relationship with cTnI levels in acute heart failure remains unknown. 


\section{BNP cut-off point in HFpEF}

In the Breathing Not Properly (BNP) Multinational Study, renal function correlated weakly with BNP levels, but more importantly it influenced the optimal BNP cut-off point [19]. Therefore, the ESC working group recommended an alternative cut-off point of $200-250 \mathrm{pg} / \mathrm{ml}$ to be considered in these patients [20].

Obesity also impacts BNP levels, even in subjects without heart failure. In the Framingham Study, multivariableadjusted mean plasma BNP levels in lean $\left(<25 \mathrm{~kg} / \mathrm{m}^{2}\right)$, overweight $\left(25-29.9 \mathrm{~kg} / \mathrm{m}^{2}\right)$, and obese $\left(\geq 30 \mathrm{~kg} / \mathrm{m}^{2}\right)$ subjects were 21.4, 15.5 and $12.7 \mathrm{pg} / \mathrm{ml}$, respectively [21]. Not only obesity but also diabetes was associated with lower plasma BNP levels [21]. Ideally, these clinical aspects need to be taken into account when assessing a patient's BNP level; however the attending clinician clearly favours a single cut-off point.

Van Veldhuisen et al. [22] reported that although the BNP levels are lower in HFpEF patients compared with HFrEF patients, the prognosis in both patient groups is comparable given a certain BNP value. These findings were recently strengthened by the same observation by Kang et al. [23]. Whether natriuretic peptides are the best biomarkers to predict outcome in the low range is less well studied. Meijers et al. recently investigated whether and what biomarkers could assess low risk in patients with heart failure. Low levels of BNP or NT-proBNP did not strongly predict outcomes in these patients, whereas other biomarkers performed better and identified patients with a low risk for an adverse outcome [24].

\section{Clinical implementation: HFpEF with low versus high BNP}

Our results show no apparent differences between the two patient groups in the frequency of comorbidities, except for BMI levels. As mentioned above, BNP levels decrease in obese patients [21]; thus, these patients may still suffer from HFpEF despite their (pseudo) lower BNP levels. These observations of the current study raise important questions regarding the use and interpretation of BNP levels as a biomarker for HFpEF.

The exact condition of 'HFpEF' patients with low BNP levels remains unclear, resulting in a dilemma for clinical practice when it comes to how to work up and how to treat these patients. Recently it was demonstrated that comorbidities might also influence the response to BNP-guided therapy [25]. Our data suggest that the clinical work-up should probably be identical, as the clinical risk factor, the physical and mental unwell-being and the outcomes are almost identical. In particular, similar to patients with 'real' HFpEF, their physical functioning is low, and regardless of possible pharmacological treatment, these patients may likely benefit from exercise treatment, and referral to a rehabilitation centre would be advised [26]. Weight loss may paradoxically lead to an increase in BNP levels but a better performance score.

\section{Strengths and limitations}

This post-hoc study has several limitations. We defined $\mathrm{HFpEF}$ as an LVEF $\geq 40 \%[27,28]$, realising that the optimal LVEF cut-off point is a matter of debate. The COACH study was performed before the era when echocardiography was a necessity for heart failure diagnostics and therefore the echocardiography data presented in this study cannot provide exact phenotyping of HFpEF patients. It could be suggested to measure BNP levels serially and use changes in BNP levels over time, instead of a single measurement, to diagnose HFpEF; unfortunately we could not address this issue. The sample size was small and these data should be regarded as hypothesis generating. However, due to the scarce data of HFpEF patients with low and high BNP, and as far as we are informed, our data are the first to address this subpopulation. Further, using our sample we were able to demonstrate significant differences which appear biologically plausible, especially the difference in BMI.

Another strength of the study is that we enrolled reallife patients presenting with dyspnoea in specialised heart failure centres.

\section{Conclusion}

Patients with heart failure and a preserved ejection fraction and plasma BNP levels $<100 \mathrm{pg} / \mathrm{ml}$ have the same clinical characteristics, an equal number and frequency of comorbidities, equally severe heart failure symptoms with impaired QoL, and the same poor outcome, when compared with patients with heart failure and a preserved ejection fraction and BNP levels $\geq 100 \mathrm{pg} / \mathrm{ml}$. The major difference between the two groups was a higher BMI in HFpEF patients with low BNP. It should be considered to evaluate and treat patients with suspected HFpEF and BNP levels below the ESC guideline threshold in a comparable manner to that used for 'official' HFpEF patients.

Sources of funding This work was supported by an Innovational Research Incentives Scheme program of the Netherlands Organization for Scientific Research (VIDI grant 917.13.350), to RAdB and by the Netherlands Heart Foundation (grant 2015T034) to WCM. The COACH trial was supported by grant $2000 \mathrm{Z} 003$ from the Netherlands Heart Foundation and by additional unrestricted grants from Biosite France SAS (Jouy-en-Josas, France), Roche Diagnostics Nederland BV (Venlo, the Netherlands), and Novartis Pharma BV (Arnhem, the Netherlands). 


\title{
Advertisement placed here.
}

\author{
CSS Bohn

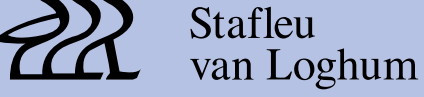 \\ Springer Media
}

Houten 2015 


\title{
Advertisement placed here.
}

\author{
CSS Bohn

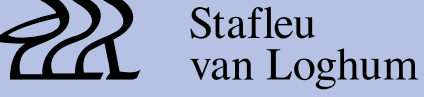 \\ Springer Media
}

Houten 2015 
Open Access This article is distributed under the terms of the Creative Commons Attribution 4.0 International License (http://creativecommons.org/licenses/by/4.0/), which permits unrestricted use, distribution, and reproduction in any medium, provided you give appropriate credit to the original author(s) and the source, provide a link to the Creative Commons license, and indicate if changes were made.

Conflict of interests None declared.

\section{References}

1. Lam CS, Donal E, Kraigher-Krainer E, Vasan RS. Epidemiology and clinical course of heart failure with preserved ejection fraction. Eur J Heart Fail. 2011;13:18-28.

2. Owan TE, Hodge DO, Herges RM, Jacobsen SJ, Roger VL, Redfield MM. Trends in prevalence and outcome of heart failure with preserved ejection fraction. N Engl J Med. 2006;355:251-9.

3. Jaarsma T, Halfens R, Abu-Saad HH, Dracup K, Stappers J, Ree $\mathrm{J}$ van. Quality of life in older patients with systolic and diastolic heart failure. Eur J Heart Fail. 1999;1:151-60.

4. Mentz RJ, Kelly JP, Lueder TG von, et al. Noncardiac comorbidities in heart failure with reduced versus preserved ejection fraction. J Am Coll Cardiol. 2014;64:2281-93.

5. Brouwers FP, Boer RA de, Harst P van der, et al. Incidence and epidemiology of new onset heart failure with preserved vs. reduced ejection fraction in a community-based cohort: 11-year follow-up of PREVEND. Eur Heart J. 2013;34:1424-31.

6. McMurray JJ, Adamopoulos S, Anker SD, et al. ESC Guidelines for the diagnosis and treatment of acute and chronic heart failure 2012: the Task Force for the Diagnosis and Treatment of Acute and Chronic Heart Failure 2012 of the European Society of Cardiology. Developed in collaboration with the Heart Failure Association (HFA) of the ESC. Eur Heart J. 2012;33:1787-847.

7. Roberts E, Ludman AJ, Dworzynski K, et al. The diagnostic accuracy of the natriuretic peptides in heart failure: systematic review and diagnostic meta-analysis in the acute care setting. BMJ. 2015;350:h910.

8. Jaarsma T, Van Der Wal MH, Hogenhuis J, et al. Design and methodology of the COACH study: a multicenter randomised Coordinating study evaluating Outcomes of Advising and Counselling in Heart failure. Eur J Heart Fail. 2004;6:227-33.

9. Jaarsma T, Wal MH van der, Lesman-Leegte I, et al. Effect of moderate or intensive disease management program on outcome in patients with heart failure: coordinating Study Evaluating Outcomes of Advising and Counseling in Heart Failure $(\mathrm{COACH})$. Arch Intern Med. 2008;168:316-24.

10. Hoekstra T, Lesman-Leegte I, Veldhuisen DJ van, Sanderman R, Jaarsma T. Quality of life is impaired similarly in heart failure patients with preserved and reduced ejection fraction. Eur $\mathrm{J}$ Heart Fail. 2011;9:1013-5.

11. Meijers WC, Januzzi JL, deFilippi C, et al. Elevated plasma galectin-3 is associated with near-term rehospitalization in heart failure: a pooled analysis of 3 clinical trials. Am Heart J. 2014;167:853-60.

12. Jenkins LS, Brodsky M, Schron E, et al. Quality of life in atrial fibrillation: the Atrial Fibrillation Follow-up Investigation of Rhythm Management (AFFIRM) study. Am Heart J. 2005;149:112-20.
13. VanderZee KI, Sanderman R, Heyink JW, Haes H de. Psychometric qualities of the RAND 36-Item Health Survey 1.0: a multidimensional measure of general health status. Int J Behav Med. 1996;3:104-22.

14. Yamamoto K, Sakata Y, Ohtani T, Takeda Y, Mano T. Heart failure with preserved ejection fraction. Circ J. 2009;73:404-10.

15. Paulus WJ, Tschope C. A novel paradigm for heart failure with preserved ejection fraction: comorbidities drive myocardial dysfunction and remodeling through coronary microvascular endothelial inflammation. J Am Coll Cardiol. 2013;62:263-71.

16. Frankenstein L, Remppis A, Nelles M, et al. Relation of N-terminal pro-brain natriuretic peptide levels and their prognostic power in chronic stable heart failure to obesity status. Eur Heart J. 2008;29:2634-40.

17. Das SR, Drazner MH, Dries DL, et al. Impact of body mass and body composition on circulating levels of natriuretic peptides: results from the Dallas Heart Study. Circulation. 2005;112:2163-8.

18. Peacock WF 4th, De Marco T, Fonarow GC, et al. Cardiac troponin and outcome in acute heart failure. $\mathrm{N}$ Engl $\mathrm{J}$ Med. 2008;358:2117-26.

19. McCullough PA, Duc P, Omland T, et al. B-type natriuretic peptide and renal function in the diagnosis of heart failure: an analysis from the Breathing Not Properly Multinational Study. Am J Kidney Dis. 2003;41:571-9.

20. Thygesen K, Mair J, Mueller C, et al. Recommendations for the use of natriuretic peptides in acute cardiac care: a position statement from the Study Group on Biomarkers in Cardiology of the ESC Working Group on Acute Cardiac Care. Eur Heart J. 2012;33:2001-6.

21. Wang TJ, Larson MG, Levy D, et al. Impact of obesity on plasma natriuretic peptide levels. Circulation. 2004;109:594-600.

22. van Veldhuisen DJ, Linssen GC, Jaarsma T, et al. B-type natriuretic peptide and prognosis in heart failure patients with preserved and reduced ejection fraction. J Am Coll Cardiol. 2013;61:1498-506.

23. Kang SH, Park JJ, Choi DJ, et al. Prognostic value of NT-proB$\mathrm{NP}$ in heart failure with preserved versus reduced EF. Heart. 2015;101:1881-8.

24. Meijers WC, de Boer RA, van Veldhuisen DJ, et al. Biomarkers and low risk in heart failure. Data from COACH and TRIUMPH. Eur J Heart Fail. 2015;17:1271-82.

25. Brunner-La Rocca HP, Eurlings L, Richards AM, et al. Which heart failure patients profit from natriuretic peptide guided therapy? A meta-analysis from individual patient data of randomized trials. Eur J Heart Fail. 2015;17:1252-61.

26. Edelmann F, Gelbrich G, Dungen HD, et al. Exercise training improves exercise capacity and diastolic function in patients with heart failure with preserved ejection fraction: results of the ExDHF (Exercise training in Diastolic Heart Failure) pilot study. J Am Coll Cardiol. 2011;58:1780-91.

27. Lewis EF, Lamas GA, O'Meara E, et al. Characterization of healthrelated quality of life in heart failure patients with preserved versus low ejection fraction in CHARM. Eur J Heart Fail. 2007;9:83-91.

28. Caughey MC, Avery CL, Ni H, et al. Outcomes of patients with anemia and acute decompensated heart failure with preserved versus reduced ejection fraction (from the ARIC study community surveillance). Am J Cardiol. 2014;114:1850-4. 